\title{
Performance of direct seeded rice in Tungabhadra command area of Karnataka
}

\author{
Y. M. Ramesha ${ }^{1}$, Manjunath Bhanuvally ${ }^{2}$ and Ashok Kumar Gaddi ${ }^{2}$ \\ ${ }^{1}$ Department of Agronomy, Agricultural Research Station, Dhadesugur, University of Agricultural Sciences, \\ Raichur (Karnataka), INDIA \\ ${ }^{2}$ Department of Soil Science and Agricultural Chemistry, Agricultural Research Station, Dhadesugur, University of \\ Agricultural Sciences, Raichur (Karnataka), INDIA \\ *Corresponding author. E-mail: rameshaym@gmail.com
}

Received: December 2, 2016; Revised received: May 31, 2017; Accepted: November 8, 2017

\begin{abstract}
A large scale demonstration was taken on direct seeded rice in four locations (one at ARS, and three at Farmers field in 50 acres each) in and around the Agricultural Research Station, Dhadesugur, University of Agricultural Sciences, Raichur, Karnataka. Our analysis showed that, the yield performance of direct seeded rice (DSR) varied with transplanted rice (TPR) and with different locations. This may be due to variety used and crop management practices adopted by the farmers. In L2, maximum grain yield was recorded in DSR (6500 kg/ha) and TPR (6200 kg/ ha) compared to other three locations. Further, the grain yield was higher in DSR compared to TPR in all the locations. Similarly, economics of DSR varied with TPR and with different locations. This may be due to yield variation at different locations. In L2, net returns and B:C ratio were higher in DSR (' 93628/ha and 3.93, respectively) and TPR ('79868/ ha and 3.0, respectively) compared to other three locations. Further, net returns and $B: C$ ratio were higher in DSR compared to TPR. Further, $47 \%$ of the labour requirement was saved in DSR compared to TPR. Therefore, concluded that, farmers can grow rice by direct seeding instead of planting to save the labour and the expenditure.
\end{abstract}

Keywords: Direct seeded rice, Grain yield, Labour, Net returns, Transplanted rice

\section{INTRODUCTION}

Rice (Oryza sativa L.) is widely grown in tropical and subtropical regions. It is staple food of India and South Asia. According to IRRI, rice is the staple food of more than three billion people in the world, most of who live in Asia. It is important energy source of more than half of the world and $65 \%$ of the Indian population (Singh et al., 2012). The way DSR is currently practiced differs considerably in different countries. Land preparation (tillage), establishment methods, seed rate, water management, weed management, and nutrient management vary from location to location. For example, seeding rates range from 6.0 to $12 \mathrm{~kg} / \mathrm{ha}$ in Karnataka and India. Cleaning and trimming of bunds are an important component of field preparation for both weed and water management in DSR (Weerakoon et al., 2011). A mix of traditional and modern practices based on farmers' long experiences and research innovations are being followed. Although a wealth of available information can lead us to develop DSR technologies that are suitable for wider agro-ecological conditions, more innovations are needed in the context of emerging challenges that future rice cultivation is likely to face.

During the past decade or so, there have been numerous efforts to find alternatives to the conventional practice of transplanted paddy (Ladha et al., 2009). Many of these studies have also considered ways to avoid or minimize extensive land preparation/tillage, which most farmers currently practice. In addition, there is a rich body of literature on case studies of DSR from countries where it is practiced widely. We believe that a systematic inventory and critical review of past and recent work would provide insight to enable us to develop efficient and viable rice production systems needed in the twenty first century. Therefore, the purpose of this study is to know the performance in Tungabhadra command area of Karnataka. Specifically, we (1) analyze the reasons for a shift from puddled transplanting to DSR, (2) compare the performance of DSR with Transplanted paddy, (3) summarize the technological package of DSR and (4) suggest future research needs for making direct-seeding systems more productive and sustainable.

\section{MATERIALS AND METHODS}

Agricultural Research Station, Dhadesugur, University of Agricultural Sciences (UAS), Raichur, Karnataka, India is situated at 15.6' $\mathrm{N}$ latitude and 76.8' E longitude with an altitude of $358 \mathrm{~m}$ above mean sea level. The soil was shallow medium black clay in texture having a pH of 8.1, organic Carbon $0.21 \%$, total N $160 \mathrm{~kg} / \mathrm{ha}$, available $\mathrm{P} 26.0 \mathrm{~kg} / \mathrm{ha}$ and available K $486 \mathrm{~kg} / \mathrm{ha}$. The 
demonstration on direct seeded rice was taken in four locations (L1. ARS, Dhadesugur, L2. Farmer Shri Khasim Saab field, L3. Farmer Shree Raghavarao field and L4. Farmer Shree Channabasava field) in and around the ARS, Dhadesugur, Raichur Dist, Karnataka with an area of 50 acres each. Fields are precisely levelled using a laser leveller with about $0.2 \%$ slope to ensure proper drainage and precise water control for achieving a good crop stand. For direct seeded rice, a weed-free, firm, and well-pulverized seedbed is prepared, which ensures adequate seed-to-soil contact for a uniform crop stand. For the reduced-till system, either a spring or a fall/autumn stale seedbed is practiced in which emerged weeds are killed with non-selective herbicides (paraquat or glyphosate) prior to rice seed sowing. Seeds rates were varying from 7 to $12 \mathrm{~kg} \mathrm{ha}^{-1}$ were drilled by using seed dril at a shallow depth $(<2.5 \mathrm{~cm})$ to achieve a final plant population of 100-160 plants $\mathrm{m}^{-2}$. A $10 \%$ higher seed rate was used when soil is saline. All rice fields were fully irrigated with precise and controlled water management. Land levelling plays a major role in precise water management. In dry seeding, the field is kept moist in the early season to ensure optimal germination of seeds, followed by a temporary flood of $2-5 \mathrm{~cm}$ (Alternate drying and wetting) throughout the growing season. At panicle development, it is critical to maintain field capacity to avoid a yield loss. Pinpoint water management is the most common one. In direct seeded rice, all $\mathrm{P}, \mathrm{K}, \mathrm{Zn}$, and $\mathrm{Fe}$ are applied as basal and $50 \%$ $\mathrm{N}$ was applied after one month of sowing and remaining $50 \% \mathrm{~N}$ was applied at two split doses $(25 \%$ in each application). Weeds werer controlled in an integrated manner by employing mechanical, cultural (certified seeds, crop rotation, good seedbed, land levelling, and precise water management), and chemical practices. However, the availability of a range of pre and post-emergence herbicides has played a major role in keeping weeds under control in direct seeded rice. Early seasonal weed control is critical for DSR success; therefore, pre-emergence herbicides with residual effects are used for achieving initial good control. The rice varieties used for direct seeded rice were BPT-5204, Nellur sona, RNR 15042, IR-64, Gangavathi sona etc., of 135 to 150 days duration. The dry paddy seeds were sown in the $1^{\text {st }}$ and $2^{\text {nd }}$ week of June, 2015 by using paddy seed drill. For observation, paddy from each plot in each farmers field was harvested and dried. The grains after threshing were weighed and recorded as grain yield per plot. Further, this plot grain yield was converted to grain yield per hectare.

\section{RESULTS AND DISCUSSION}

Yield performance of DSR and TPR: Our analysis showed that, the yield performance of DSR varied with TPR and with different locations. This may be due to variety used and crop management practices adopted by the farmers. In Farmer Shri Khasim Saab field, grain yield was higher in DSR (6500 kg/ha) and TPR $(6200 \mathrm{~kg} / \mathrm{ha})$ compared to other three locations. Further, the average grain yield $(5625 \mathrm{~kg} / \mathrm{ha})$ was higher in DSR compared to TPR $(5425 \mathrm{~kg} / \mathrm{ha})$ in all the locations (Table 1). In general, DSR yielded similar to TPR in Cambodia (Rickman et al., 2001). Similarly, Mitchell et al. (2004) reported that DSR performed similar to TPR also in Laos, Thailand, and Cambodia. It is also important to note that the performance of DSR can also vary from location to location within a country. A possible reason for this differential performance in different locations was may be the different management practices adopted. Flooding of rice after successful establishment can alleviate nutrient deficiencies (i.e., Fe and $\mathrm{Zn}$ ) and soil -borne diseases (i.e., nematodes). Therefore, it is easier to achieve equivalent yield with DSR. The increased yield in DSR compared to TPR in different locations may include (1) adequate weed control, (2) higher seeds per panicle than in puddled transplanting, (3) lower crop lodging and (4) Efficient utilization and management of water and nutrient (especially micronutrient deficiencies). In studies in which, equivalent or higher yields are often reported under DSR than in TPR (Bhushan et al., 2007). Technologies have been developed or progress has been made to overcome some of the constraints in DSR. For example, (1) coating of pre-germinated seeds with calciumperoxide to facilitate seedling establishment in anaerobic conditions in wet seeding or water seeding, (2) the development of new-generation precise seeding and land-leveling machinery for dry drill seeding (Gopal et al., 2010), (3) integrated weed management (IWM), including the use of effective herbicides and non-chemical methods for weed control (Chauhan and Johnson, 2010).

Economics of DSR and TPR: Our studies showed that (Table 2), the economics of DSR varied with TPR and with different locations. This may be due to yield variation at different locations. In Farmer Shri Khasim Saab field, net returns and $\mathrm{B}: \mathrm{C}$ ratio were higher in DSR (93628/ha and 3.93, respectively) and TPR (79868/ha and 3.0, respectively) compared to other three locations. Further, the average net returns ( $77265 /$ ha) and B:C ratio (3.45) were higher in DSR compared to TPR ( $66166 /$ ha and 2.70 , respectively). A major reason for farmers' interest in DSR is the decreasing cost of cultivation and increasing profits. Farmers likely prefer a technology that gives higher profit despite similar or slightly lower yield. Overall analysis of four locations studies shows that various methods of direct seeding reduced the cost of production by $` 5000$ to $` 10000$ per hectare compared with conventional practice (TPR) (Table 2). The cost reductions were largely due to either reduced labor cost or tillage cost or both under DSR (Kumar et al., 
Table 1. The yield performance of DSR and TPR.

\begin{tabular}{|c|c|c|c|c|c|c|}
\hline \multirow{2}{*}{$\begin{array}{l}\text { Sl. } \\
\text { No. }\end{array}$} & \multirow[t]{2}{*}{ Locations } & \multirow{2}{*}{$\begin{array}{c}\text { Varieties } \\
\text { used }\end{array}$} & \multicolumn{2}{|c|}{ Grain yield (kg/ha) } & \multicolumn{2}{|c|}{ Straw yield (kg/ha) } \\
\hline & & & DSR & TPR & DSR & TPR \\
\hline 1 & ARS, Dhadesugur & $\begin{array}{c}\text { Gangavathi } \\
\text { Sona }\end{array}$ & 5200 & 5000 & 5780 & 5580 \\
\hline 2 & Farmer Shri Khasim Saab field & Nellur Sona & 6500 & 6200 & 7190 & 6890 \\
\hline 3 & Farmer Shri Raghavarao field & RNR 15042 & 5500 & 5300 & 6150 & 5930 \\
\hline 4 & Farmer Shri Channabasav Uppal field & BPT 5204 & 5300 & 5200 & 5930 & 5820 \\
\hline 5 & Average & - & 5625 & 5425 & 6262.5 & 6055 \\
\hline
\end{tabular}

Table 2. The economic performance of DSR and TPR.

\begin{tabular}{|c|c|c|c|c|c|c|c|c|c|}
\hline \multirow[t]{2}{*}{$\begin{array}{l}\text { Sl. } \\
\text { No. }\end{array}$} & \multirow[t]{2}{*}{ Locations } & \multicolumn{2}{|c|}{$\begin{array}{c}\text { Cost of cultivation } \\
\text { (/ha) }\end{array}$} & \multicolumn{2}{|c|}{$\begin{array}{l}\text { Gross returns } \\
\text { (/ha) }\end{array}$} & \multicolumn{2}{|c|}{ Net returns ("/ha) } & \multicolumn{2}{|c|}{ B:C ratio } \\
\hline & & DSR & TPR & DSR & TPR & DSR & TPR & DSR & TPR \\
\hline 1 & ARS, Dhadesugur & 30000 & 35000 & 100536 & 96696 & 70536 & 61696 & 3.35 & 2.76 \\
\hline 2 & $\begin{array}{l}\text { Farmer Shri } \\
\text { Khasim Saab field }\end{array}$ & 32000 & 40000 & 125628 & 119868 & 93628 & 79868 & 3.93 & 3.00 \\
\hline 3 & $\begin{array}{l}\text { Farmer Shri } \\
\text { Raghavarao field }\end{array}$ & 32000 & 40000 & 106380 & 102516 & 74380 & 62516 & 3.32 & 2.56 \\
\hline 4 & $\begin{array}{l}\text { Farmer Shri Chan- } \\
\text { nabasav Uppal } \\
\text { field }\end{array}$ & 32000 & 40000 & 102516 & 100584 & 70516 & 60584 & 3.20 & 2.51 \\
\hline 5 & Average & 31500 & 38750 & 108765 & 104916 & 77265 & 66166 & 3.45 & 2.70 \\
\hline
\end{tabular}

Table 3. The labour requirement for DSR and TPR.

\begin{tabular}{clcc}
\hline Sl. No. & Total labour requirement per hectare & DSR & TPR \\
\hline 1 & Nursery & - & 5 \\
2 & Seedling uprooting & - & 5 \\
3 & Land preparation & - & 5 \\
4 & Sowing/transplanting & 2 & 25 \\
5 & Weeding & 40 & 30 \\
6 & Irrigation (Entire crop growth period) & 16 & 16 \\
7 & Harvesting/threshing & 2 & 2 \\
\hline 8 & Total & 60 & 88 \\
$\mathbf{9}$ & \% saving & $\mathbf{4 7}$ \% & $\mathbf{0}$ \\
\hline
\end{tabular}

2009). However, these reduced costs did not always translate into increased profitability. Increases in net returns in DSR compared to TPR were highly variable, ranging from by `5000 to ` 10000 per hectare, primarily because of large yield variability. Overall, DSR was either more profitable than or equally profitable as puddled transplanted rice. The labour and water costs are likely to increase in future which will make DSR economically more attractive to the farmers.

Labor use in DSR and TPR: DSR is a labour-saving technology compared to TPR. Large variations in total labour requirement for various field operations for diverse practices were reported (Table 3), which may largely be due to differences in the level of mechanization used. Depending on the method of land preparation, the labour requirement in DSR savings of $47 \%$ compared with TPR. The variation reported by different locations in labour savings primarily depends on labor used in weed control. Labor use is higher (33 $\%$ ) for controlling weeds in DSR than in TPR. If weeds are controlled effectively with herbicides, the labor savings can be substantial. Direct seeding avoids nursery raising, seedling uprooting, and transplanting, and thus reduces the labor requirement. DSR also a voids puddling operations, and thus further saves labor use. Since land preparation is mostly mechanized, 
there is more savings in machine labor than in human labor in this operation (Bhushan et al., 2007; Saharawat et al., 2010). In addition to labor savings, the demand for labor is spread out over a longer period in DSR than in transplanted rice. Conventional practice (TPR) requires much labor in the critical operation of transplanting, which often results in a shortage of labor. The spread-out labor requirement helps in making full use of family labor and having less dependence on hired labor.

Benefits and risks of direct-seeded rice: Directseeding of rice has the potential to provide several benefits to farmers and the environment over conventional practices of puddling and transplanting. However, it is also important to understand and predict possible risks or threats that direct seeding may have in the long run. The following general benefits of DSR are (1) Labor savings up to $47 \%$, (2) Reduces drudgery by eliminating transplanting operation, (3) Water savings ranged from $12 \%$ to $35 \%$ depending on soil type, (4) Reduces irrigation water loss through percolation due to fewer soil cracks, (5) Reduces cost of cultivation, (6) Increases the total income of farmers, (8) Allows timely planting of subsequent crop due to early harvest of direct seeded rice crop by 7-14 days and the general risks of DSR are (1) Sudden rain immediately after seeding can adversely affect crop establishment, (2) Reduces availability of soil nutrients such as N, Fe, and $\mathrm{Zn}$, (3) Appearance of new weeds, (4) Increases dependence on herbicides, (5) Increases incidence of new soil-borne pests and diseases such as nematodes, (6) Enhances nitrous oxide emissions from soil and (7). Relatively more soil Carbon loss due to frequent wetting and drying.

\section{Conclusion}

Results indicated that, Farmers can grow rice by direct seeding instead of planting. So that, grain and straw yield of rice was increases with reduced resources. Further, Net returns and benefit cost ratio were also higher in direct seeded rice compared to transplanted rice.

\section{REFERENCES}

Bhushan, Lav, Ladha, J. K., Gupta, R. K., Singh, S.,
Tirol-Padre, A., Saharawat, Y. S., Gathala, M., and Pathak, H. (2007). Saving of water and labor in rice-wheat systems with no-tillage and direct seeding technologies. Agron. J., 99: 1288-1296.

Chauhan, B. S., and Johnson, D. E. (2010). The role of seed ecology in improving weed management strategies in the tropics. Adv. Agron. 105, 221-262.

Gopal, R., Jat, R. K., Malik, R. K., Kumar, V., Alam, M. M., Jat, M. L., Mazid, M. A., Saharawat, Y. S., McDonald, A., and Gupta, R. (2010). Direct Dry Seeded Rice Production Technology and Weed Management in Rice Based Systems. Technical Bulletin. International Maize and Wheat Improvement Center, New Delhi, India, $28 \mathrm{pp}$.

Kumar, V., Ladha, J. K., and Gathala, M. K. (2009). Direct drill-seeded rice: A need of the day. In "Annual Meeting of Agronomy Society of America, Pittsburgh, November 1 -5 .

Ladha, J. K., Kumar, V., Alam, M. M., Sharma, S., Gathala, M., Chandna, P., Saharawat, Y. S., and Balasubramanian, V. (2009). Integrating crop and resource management technologies for enhanced productivity, profitability, and sustainability of the rice-wheat system in South Asia. In "Integrated Crop and Resource Management in the Rice-Wheat System of South Asia" (J. K. Ladha, Y. Singh, O. Erenstein, and B. Hardy, Eds.), pp. 69-108. International Rice Research Institute, Los Bañ os, Philippines.

Mitchell, J., Fukai, S., and Basnayake, J. (2004). Grain yield of direct seeded and transplanted rice in rainfed lowlands of South East Asia. In "Proceedings of 4th International Crop Science Congress," 26 September-October 2004, Brisbane, Queensland, Australia (on CD).

Rickman, J. F., Pyseth, M., Bunna, S., and Sinath, P. (2001). Direct seeding of rice in Cambodia. In "Proceedings of an International Workshop", 30 October-2 November. ACIAR Proceedings No. 101, Vientiane, Laos.

Saharawat, Y. S., Singh, Bhagat, Malik, R. K., Ladha, J. K., Gathala, M., Jat, M. L., and Kumar, V. (2010). Evaluation of alternative tillage and crop establishment methods in a rice-wheat rotation in North Western IGP. Field Crops Res., 116, 260-267.

Singh, A. K., Chandra, N., and Bharati, R. C. (2012). Effects genotypes and planting time on phenology and performance of rice (Oryza sativa L.). Vegetos, 25, 151156.

Weerakoon,W.M.W., Mutunayake, M. M. P., Bandara, C., Rao, A. N., Bhandari, D. C., and Ladha, J. K. (2011). Direct-seeded rice culture in Sri Lanka. Field Crops Res. 121, 53-63. 